OPEN ACCESS

Edited by:

R. Keith Reeves,

Harvard Medical School,

United States

Reviewed by:

Gunnur Deniz,

Istanbul University, Turkey

Ahmed Lasfar,

Rutgers University, The State

University of New Jersey,

United States

*Correspondence:

Jianming Wu

jmwu@umn.edu

Bruce Walcheck

walch003@umn.edu

Specialty section: This article was submitted to

Molecular Innate Immunity,

a section of the journal

Frontiers in Immunology

Received: 27 September 2018 Accepted: 22 November 2018

Published: 06 December 2018

Citation:

Snyder KM, Hullsiek R, Mishra HK,

Mendez DC, Li Y, Rogich A,

Kaufman DS, Wu J and Walcheck $B$

(2018) Expression of a Recombinant

High Affinity IgG FC Receptor by

Engineered NK Cells as a Docking

Platform for Therapeutic mAbs to

Target Cancer Cells.

Front. Immunol. 9:2873.

doi: 10.3389/fimmu.2018.02873

\section{Expression of a Recombinant High Affinity IgG Fc Receptor by Engineered NK Cells as a Docking Platform for Therapeutic mAbs to Target Cancer Cells}

\author{
Kristin M. Snyder ${ }^{1}$, Robert Hullsiek ${ }^{1}$, Hemant K. Mishra ${ }^{1}$, Daniel C. Mendez ${ }^{1}$, Yunfang Li ${ }^{1}$, \\ Allison Rogich ${ }^{1}$, Dan S. Kaufman ${ }^{2}$, Jianming $W^{1 *}$ and Bruce Walcheck ${ }^{1 *}$ \\ ${ }^{1}$ Department of Veterinary and Biomedical Sciences, University of Minnesota, St. Paul, MN, United States, ${ }^{2}$ Department of \\ Medicine, University of California, San Diego, San Diego, CA, United States
}

Anti-tumor mAbs are the most widely used and characterized cancer immunotherapy. Despite having a significant impact on some malignancies, most cancer patients respond poorly or develop resistance to this therapy. A known mechanism of action of these therapeutic mAbs is antibody-dependent cell-mediated cytotoxicity (ADCC), a key effector function of human NK cells. CD16A on human NK cells has an exclusive role in binding to tumor-bound IgG antibodies. Though CD16A is a potent activating receptor, it is also a low affinity lgG $F c$ receptor $(F C \gamma R)$ that undergoes a rapid downregulation in expression by a proteolytic process involving ADAM17 upon NK cell activation. These regulatory processes are likely to limit the efficacy of tumor-targeting therapeutic mAbs in the tumor environment. We sought to enhance NK cell binding to anti-tumor mAbs by engineering these cells with a recombinant $F_{c} \gamma R$ consisting of the extracellular region of CD64, the highest affinity Fc $\gamma R$ expressed by leukocytes, and the transmembrane and cytoplasmic regions of CD16A. This novel recombinant Fc $\gamma \mathrm{R}(\mathrm{CD} 64 / 16 \mathrm{~A})$ was expressed in the human NK cell line NK92 and in induced pluripotent stem cells from which primary NK cells were derived. CD64/16A lacked the ADAM17 cleavage region in CD16A and it was not rapidly downregulated in expression following NK cell activation during ADCC. CD64/16A on NK cells facilitated conjugation to antibody-treated tumor cells, ADCC, and cytokine production, demonstrating functional activity by its two components. Unlike NK cells expressing CD16A, CD64/16A captured soluble therapeutic mAbs and the modified NK cells mediated tumor cell killing. Hence, CD64/16A could potentially be used as a docking platform on engineered NK cells for therapeutic mAbs and IgG Fc chimeric proteins, allowing for switchable targeting elements and a novel cancer cellular therapy.

Keywords: FcR, ADCC, NK cell, immunotherapy, antibody 


\section{INTRODUCTION}

Natural killer (NK) cells are cytotoxic lymphocytes of the innate immune system that target stressed, infected, and neoplastic cells (1). In contrast to the diverse array of receptors involved in natural cytotoxicity, human NK cells mediate ADCC exclusively through the IgG Fc receptor CD16A (Fc $\gamma$ RIIIA) (2-4). This is a potent activating receptor and its signal transduction involves the association of the transmembrane and cytoplasmic

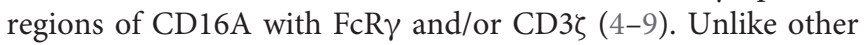
activating receptors expressed by NK cells, the cell surface levels of CD16A undergo a rapid downregulation upon NK cell activation during ADCC and by other stimuli (10-14). CD16A downregulation also occurs in the tumor environment of patients and contributes to NK cell dysfunction (15-19). A disintegrin and metalloproteinase-17 (ADAM17) expressed by NK cells plays a key role in its downregulation by cleaving CD16A in a cis manner at a specific location proximal to the cell membrane upon NK cell activation $(13,14,20)$.

There are two allelic variants of CD16A that have either a phenylalanine or valine residue at position 176 (position 158 if amino acid enumeration does not include the signal sequence). The CD16A-176V variant has a higher affinity for $\operatorname{IgG}(21$, 22 ), but CD16A-176F is the dominant allele in humans (23). Clinical analyses have revealed a positive correlation between the therapeutic efficacy of tumor-targeting therapeutic $\mathrm{mAbs}$ and CD16A binding affinity. Patients homozygous for the CD16A valine variant $(\mathrm{CD} 16 \mathrm{~A}-\mathrm{V} / \mathrm{V})$ had an improved clinical outcome after treatment with anti-tumor mAbs compared to those who were either heterozygous $(\mathrm{CD} 16 \mathrm{~A}-\mathrm{V} / \mathrm{F})$ or homozygous (CD16A-F/F) for the lower affinity FcyRIIIA isoform [as reviewed in Wang et al. (4)]. These findings establish that increasing the binding affinity of CD16A for anti-tumor mAbs may lead to improved cancer cell killing.

CD64 (Fc $\gamma$ R1) binds to monomeric IgG with 2-3 orders of magnitude higher affinity than CD16A (24-26). CD64 recognizes the same IgG isotypes as $\mathrm{CD} 16 \mathrm{~A}$ and is expressed by myeloid cells, including monocytes, macrophages, and activated neutrophils, but not NK cells $(24,26)$. We generated the novel recombinant receptor CD64/16A that consists of the extracellular region of human CD64 for high affinity antibody binding, and the transmembrane and intracellular regions of human CD16A for mediating NK cell signal transduction. CD64/16A also lacked the membrane proximal ADAM17 cleavage site found in CD16A. In this study, we stably expressed CD64/16A in NK92 cells, a cytotoxic human NK cell line that lacks endogenous Fc $\gamma$ Rs (27), and in induced pluripotent stem cells (iPSCs) that were then differentiated into primary NK cells. We show that in these two NK cell platforms, this novel recombinant $\mathrm{Fc} \gamma \mathrm{R}$ is functional and can capture soluble monomeric IgG therapeutic mAbs that provide targeting elements for tumor cell ADCC.

\section{MATERIALS AND METHODS}

\section{Antibodies}

All mAbs to human hematopoietic and leukocyte phenotypic markers are described in Table 1. All isotypematched negative control mAbs were purchased from BioLegend
TABLE 1 | Antibodies.

\begin{tabular}{|c|c|c|c|}
\hline Antigen & Clone & Fluorophore & Company \\
\hline CD56 & HCD56 & $\mathrm{PE}-\mathrm{CY} 7$ & $\begin{array}{l}\text { BioLegend, San } \\
\text { Diego, CA }\end{array}$ \\
\hline CD3 & HIT3a & PE & BioLegend \\
\hline CD16 & $3 G 8$ & APC & BioLegend \\
\hline CD16 & $3 G 8$ & none & Ancell, Bayport, MN \\
\hline CD7 & $\mathrm{CD} 7-6 \mathrm{~B} 7$ & PE/CY5 & BioLegend \\
\hline CD336/NKp44 & P44-8 & APC & BioLegend \\
\hline CD335/NKp46 & 9E2 & APC & BioLegend \\
\hline CD159a/NKG2A & Z199 & APC & $\begin{array}{l}\text { Beckman Coulter, } \\
\text { Brea, CA }\end{array}$ \\
\hline CD314/NKG2D & 1D11 & PerCP/Cy5.5 & BioLegend \\
\hline CD158a/KIR2DL1 & HP-MA4 & PE & BioLegend \\
\hline CD158b1/KIR2DL2/L3 & DX27 & PE & BioLegend \\
\hline CD158e1/KIR3DL1 & DX9 & PE & BioLegend \\
\hline CD94 & DX22 & PE & BioLegend \\
\hline CD64 & 10.1 & APC & BioLegend \\
\hline CD64 & 10.1 & none & Ancell \\
\hline CD34 & $561 z z$ & PE & BioLegend \\
\hline CD45 & 2D1 & APC & BioLegend \\
\hline CD43 & CD43-10G7 & APC & BioLegend \\
\hline CD62L/L-selectin & LAM1-116 & APC & Ancell \\
\hline
\end{tabular}

(San Diego, CA). APC-conjugated $\mathrm{F}\left(\mathrm{ab}^{\prime}\right)_{2}$ donkey antihuman or goat anti-mouse IgG $(\mathrm{H}+\mathrm{L})$ were purchased from Jackson ImmunoResearch Laboratories (West Grove, $\mathrm{PA})$. The human IgG1 mAbs trastuzumab/Herceptin and rituximab/Rituxan, manufactured by Genentech (South San Francisco, CA), and cetuximab/Erbitux, manufactured by Bristol-Myers Squibb (Lawrence, NJ), were purchased through the University of Minnesota Boynton Pharmacy. Recombinant human L-selectin/IgG1 Fc chimera was purchased from R\&D Systems (Minneapolis, $\mathrm{MN}$ ).

\section{Generation of Human CD64/16A}

Total RNA was isolated from human peripheral blood leukocytes using TRIzol total RNA isolation reagent (Invitrogen, Carlsbad, CA) and cDNA was synthesized with the SuperScript preamplification system (Invitrogen). The recombinant CD64/16A is comprised of human CD64 extracellular domain and CD16A transmembrane and cytoplasmic domains. PCR fragments for CD64 (885 bps) and CD16A (195 bps) were amplified from the generated cDNA. The PCR fragments were purified and mixed together with the forward primer 5'- CGG GAA TTC GGA GAC AAC ATG TGG TTC TTG ACA A-3 $3^{\prime}$, the reverse primer $5^{\prime}$ - CCG GAA TTC TCA TTT GTC TTG AGG GTC CTT TCT-3' (underlined nucleotides are EcoR I sites), and Pfx50 DNA polymerase (Invitrogen) to generate the recombinant $\mathrm{CD} 64 / 16 \mathrm{~A}$ receptor. CD64/CD16A and CD16A cDNA (CD16A-176V variant) was inserted into the retroviral expression vector $\mathrm{pBMN}$-IRES-EGFP and virus was generated for NK92 cell transduction, as previously described (14). For this study, the transduced NK92 cells were sorted 
by flow cytometry to derive populations with homogenous expression of CD16A or CD64/16A, but consisted of a mixed clonal population to avoid the effects of random genomic integration of vector DNA in a single NK92 transductant, as we have done in previous studies $(14,20)$. Additionally, CD64/CD16A cDNA was inserted into a pKT2 sleeping beauty transposon vector and used along with SB100X transposase for iPSC transduction, as previously described (14). The nucleotide sequences of all constructs were confirmed by direct sequencing from both directions on an ABI 377 sequencer with ABI BigDye terminator cycle sequencing kit (Applied Biosystems, Foster City, CA).

\section{Cells}

Fresh human peripheral blood leukocytes from plateletpheresis were purchased from Innovative Blood Resources (St. Paul, $\mathrm{MN})$. Peripheral blood mononuclear cells were further enriched using Ficoll-Paque Plus (GE Healthcare Bio-Sciences AB, Uppsala, Sweden) and NK cells were purified by negative depletion using an EasySep human NK cell kit (StemCell Technologies, Cambridge, MA), as per the manufacturer's instructions, with $>95 \%$ viability and $90-95 \%$ enrichment of $\mathrm{CD} 6^{+} \mathrm{CD}^{-}$lymphocytes. Viable cell counting was performed using a Countess II automated cell counter (Life Technologies Corporation, Bothell, WA). The human NK cell line NK92 and the ovarian cancer cell line SKOV-3 were obtained from ATCC (Manassas, VA) and cultured per the manufacturer's directions. The NK92 cells required IL-2 for growth (500 $\mathrm{IU} / \mathrm{ml}$ ), which was obtained from R\&D Systems and the National Cancer Institute, Biological Resources Branch, Preclinical Biologics Repository (Frederick, MD). Heat inactivated Gibco FBS was purchased from Thermo Fisher Scientific (Waltham, MA), and heat inactivated horse serum was purchased from Sigma-Aldrich (St. Louis, MO). For all assays described below, cells were used when in log growth phase.

The iPSCs UCBiPS7, derived from umbilical cord blood CD34 cells, have been previously characterized and were cultured and differentiated into hematopoietic progenitor cells as described with some modifications (14, 28-31). iPSC culture and hematopoietic differentiation was performed using TeSRE8 medium and a STEMdiff Hematopoietic Kit (StemCell Technologies), which did not require the use of mouse embryonic fibroblast feeder cells, TrypLE adaption, spin embryoid body formation, or $\mathrm{CD}_{3} 4^{+}$cell enrichment. To passage iPSCs, cells were dissociated with Gentle Cell Dissociation Reagent (StemCell Technologies) and aggregates $\geq 50 \mu \mathrm{m}$ in diameter were counted with a hemocytometer and diluted to 20-40 aggregates $/ \mathrm{ml}$ with TeSR-E8 medium. Each well of a 12-well plate was pre-coated with Matrigel Matrix (Corning Inc., Tewksbury, MA) and seeded with 40-80 aggregates in $2 \mathrm{ml}$ of TeSRE8 medium. Cell aggregates were cultured for $24 \mathrm{~h}$ before differentiation with the STEMdiff Hematopoietic Kit, as per the manufacturer's instructions. At day 12 of hematopoietic progenitor cell differentiation, the percentage of hematopoietic progenitor cells was determined using flow cytometric analysis with anti-CD34, anti-CD45, and anti-CD43 mAbs. NK cell differentiation was performed as previously described (32). The iPSC-derived NK cells, referred to here as iNK cells, were expanded for examination using $\gamma$-irradiated K562-mbIL2141BBL feeder cells at a 1:2 ratio in cell expansion medium [60\% DMEM, 30\% Ham's F12, 10\% human AB serum (Valley Biomedical, Winchester, VA), $20 \mu \mathrm{M}$ 2-mercaptoethanol, $50 \mu \mathrm{M}$ ethanolamine, $20 \mu \mathrm{g} / \mathrm{ml}$ ascorbic Acid, $5 \mathrm{ng} / \mathrm{ml}$ sodium selenite, $10 \mathrm{mM}$ HEPES, and 100-250 IU/ml IL-2 (R\&D Systems)], as described previously $(14,29-31)$.

\section{Cell Staining, IFN $\gamma$ Quantification, and Flow Cytometric Analysis}

For cell staining, $0.5 \times 10^{6}-1 \times 10^{6}$ cells were stained with the indicated $\mathrm{mAbs}$ (Table 1) using flow buffer (dPBS containing $2.5 \%$ FBS and $0.02 \%$ sodium azide) and $1 \times 10^{4}-5 \times 10^{4}$ cells per sample were acquired, as previously described $(11,14,20)$. For controls, fluorescence minus one was used as well as appropriate isotype-matched antibodies since the cells of interest expressed FcRs. A FSC-A/SSC-A plot was used to set an electronic gate on leukocyte populations and an FSC-A/FSC-H plot was used to set an electronic gate on single cells. A Zombie viability kit was used to assess live vs. dead cells, as per the manufacturer's instructions (BioLegend).

To assess the capture of soluble trastuzumab, rituximab, cetuximab, or L-selectin/Fc chimera, transduced NK cells were incubated with $5 \mu \mathrm{g} / \mathrm{ml}$ of antibody for $2 \mathrm{~h}$ at $37^{\circ} \mathrm{C}$ in MEM$\alpha$ basal media (Thermo Fisher Scientific) supplemented with IL-2 (200 IU/ml), HEPES (10 mM), and 2-mercaptoethanol $(0.1 \mathrm{mM})$, washed with MEM- $\alpha$ basal media, and then stained on ice for $30 \mathrm{~min}$ with a 1:200 dilution of APC-conjugated $\mathrm{F}\left(\mathrm{ab}^{\prime}\right)_{2}$ donkey anti-human $\operatorname{IgG}(\mathrm{H}+\mathrm{L})$. To detect recombinant human L-selectin/Fc binding, cells were stained with the anti-Lselectin mAb APC-conjugated Lam1-116. To compare CD16A and CD64/16A staining levels on NK92 cells, the respective transductants were stained with a saturating concentration of unconjugated anti-CD16 (3G8) or anti-CD64 (10.1) mAbs $(5 \mu \mathrm{g} / \mathrm{ml})$, washed extensively with $\mathrm{dPBS}$ containing $2 \%$ goat serum and $2 \mathrm{mM}$ sodium azide, and then stained with APCconjugated $\mathrm{F}\left(\mathrm{ab}^{\prime}\right)_{2}$ goat anti-mouse $\operatorname{IgG}(\mathrm{H}+\mathrm{L})$. This approach was used since directly conjugated anti-CD16 and antiCD64 mAbs can vary in their levels of fluorophore labeling. IFN $\gamma$ quantification was performed by a cytometric beadbased Flex Set assay (BD Biosciences, San Jose, CA), per the manufacturer's instructions. The minimum and maximum limit of detection for the assay was 1.8 and $2,500 \mathrm{pg} / \mathrm{ml}$, respectively. All flow cytometric analyses were performed on a FACSCelesta instrument (BD Biosciences). Data was analyzed using FACSDIVA v8 (BD Biosciences) and FlowJo v10 (Ashland, $\mathrm{OR})$.

\section{Cell-Cell Conjugation Assay and ADCC}

NK92 cells used in these assays were transduced with pBMNIRES-EGFP empty vector or vector containing CD64/16A or CD16A cDNA. For all transductants, nearly $100 \%$ of the cells expressed GFP. The NK92 transductants were initially serumstarved for $2 \mathrm{~h}$ at $37^{\circ} \mathrm{C}$ in MEM- $\alpha$ basal media (Thermo Fisher Scientific, Waltham, MA) supplemented with IL-2 (200 IU/ml), 
HEPES (10 mM), and 2-mercaptoethanol (0.1 mM). SKOV-3 cells were labeled with CellTrace Violet (Molecular Probes, Eugene, OR) per the manufacturer's instructions, incubated with $5 \mu \mathrm{g} / \mathrm{ml}$ trastuzumab for $30 \mathrm{~min}$ and washed with MEM- $\alpha$ basal media. NK92 cells and SKOV-3 cells were then resuspended in the supplemented MEM- $\alpha$ basal media at $1 \times 10^{6}$ and $2 \times$ $10^{6} / \mathrm{ml}$, respectively. For a 1:2 Effector:Target (E:T) ratio, 100 $\mu l$ of each cell type was mixed together, centrifuged for $1 \mathrm{~min}$ at $20 \times \mathrm{g}$ and incubated at $37^{\circ} \mathrm{C}$ for the indicated time points. After each time point, the cells were gently vortexed for $3 \mathrm{~s}$ and immediately fixed with $1 \%$ paraformaldehyde in dPBS at $4^{\circ} \mathrm{C}$. Cells were immediately analyzed by flow cytometry for which $2 \times$ $10^{4}$ cells per sample were acquired for analyses. The percentage of conjugated NK cells was calculated by gating on GFP and CellTrace Violet double-positive events.

To evaluate ADCC, a DELFIA EuTDA-based cytotoxicity assay was used according to the manufacturer's instructions (PerkinElmer, Waltham, MA). Briefly, target cells were labeled with Bis(acetoxymethyl)-2-2:6,2 terpyridine 6,6 dicarboxylate (BATDA) for $30 \mathrm{~min}$ in their culture medium, washed in culture medium, and pipetted into a 96-well non-tissue culture-treated U-bottom plates at a density of $8 \times 10^{3}$ cells/well. A tumor targeting $\mathrm{mAb}$ was added at the indicated concentrations and NK cells were added at the indicated E:T ratios. The plates were centrifuged at $400 \times \mathrm{g}$ for $1 \mathrm{~min}$ and then incubated for $2 \mathrm{~h}$ in a humidified $5 \% \mathrm{CO}_{2}$ atmosphere at $37^{\circ} \mathrm{C}$. At the end of the incubation, the plates were centrifuged at $500 \times \mathrm{g}$ for $5 \mathrm{~min}$ and supernatants were transferred to a 96 well DELFIA Yellow Plate (PerkinElmer) and combined with europium. Fluorescence was measured by time-resolved fluorometry using a BMG Labtech CLARIOstar plate reader (Cary, NC). BATDA-labeled target cells alone with or without therapeutic antibodies were cultured in parallel to assess spontaneous lysis and in the presence of $2 \%$ Triton-X to measure maximum lysis. ADCC for each sample is represented as Percent Specific Release and was calculated using the following formula:

Percent Specific Release $=\frac{(\text { Experimental release }- \text { Spontaneous release })}{(\text { Maximal release }- \text { Spontaneous release })} * 100$

For each experiment, measurements were conducted in triplicate using two-three replicate wells.

\section{Statistical Analyses}

Statistical analyses were performed by use of GraphPad Prism (GraphPad Software, La Jolla, CA, USA). After assessing for approximate normal distribution, all variables were summarized as mean $\pm S D$. Comparison between 2 groups was done with Student's $t$-test, with $p<0.05$ taken as statistically significant.

\section{RESULTS}

\section{Expression and Function of CD64/16A in NK92 Cells}

We engineered a recombinant $\mathrm{Fc} \gamma \mathrm{R}$ that consists of the extracellular region of human CD64 and the transmembrane and cytoplasmic regions of human CD16A, referred to as CD64/16A (Figure 1A). The human NK cell line NK92 stably expressing this recombinant receptor were initially used to examine its function. These cells lack endogenous Fc $\gamma$ Rs but can mediate ADCC when expressing recombinant CD16A $(14,20,27)$. As shown is Figure 1B, NK92 cells expressing CD64/16A were positively stained by an anti-CD64 mAb, whereas parental NK92 cells or NK92 cells expressing CD16A were not. CD16A is known to undergo ectodomain shedding upon NK cell activation resulting in its rapid downregulation in expression $(10-13,20)$. CD16A as well as its isoform CD16B on neutrophils is cleaved by ADAM17 (10), and this occurs at an extracellular region proximal to the cell membrane $(13,14)$. The ADAM17 cleavage region of CD16A is not present in CD64 or CD64/16A (Figure 1A). We found that CD16A underwent a $>50 \%$ decrease in expression upon NK92 stimulation by ADCC, whereas CD64/16A demonstrated little to no downregulation (Figure 1C).

To establish the functional activity of CD64/16A, we determined its ability to promote E:T conjugation, induce ADCC, and stimulate IFN- $\gamma$ production. SKOV-3 cells, an ovarian cancer cell line that expresses HER2, were used as the target. A two-color flow cytometric approach was used to quantify the conjugation of NK92-CD64/16A cells and SKOV-3 cells in the absence and presence of the anti-HER2 therapeutic $\mathrm{mAb}$ trastuzumab. A bicistronic vector was used for CD64/16A as well as GFP expression, and its fluorescence was used to identify the NK92 cells. SKOV-3 cells were labeled with the fluorescent dye CellTrace Violet. The incubation of NK92CD64/16A cells with SKOV-3 cells alone resulted in a low level of conjugation after $60 \mathrm{~min}$ of exposure (Figure 2A). $\mathrm{E}: \mathrm{T}$ conjugation was markedly increased in the presence of trastuzumab, and this was effectively disrupted by the presence of the anti-CD64 mAb 10.1 (Figure 2A), which blocks IgG binding (33). The addition of trastuzumab, however, did not enhance E:T conjugation by NK92 cells transduced with an empty vector expressing only GFP (NK92 control cells) (Figure 2A).

An increase in SKOV-3 cell conjugation by NK92-CD64/16A cells corresponded with increased cytolytic activity. We determined direct target cell killing by NK92-CD64/16A cells using an ADCC assay in which various concentrations of trastuzumab and E:T ratios were examined. We show in Figure 2B effective SKOV-3 cytotoxicity by NK92CD64/16A cells in the presence of trastuzumab that decreased with lower $\mathrm{mAb}$ concentrations and lower E:T ratios. To confirm the role of CD64/16A in the induction of target cell killing, we also performed the assay in the presence the anti-CD64 mAb 10.1, which effectively blocked ADCC (Figure 2C).

Cytokine production is also induced during ADCC and NK cells are major producers of $\operatorname{IFN} \gamma(4,34)$. NK92-CD64/16A cells exposed to SKOV-3 cells and trastuzumab produced considerably higher levels of IFN $\gamma$ than when exposed to SKOV-3 cells alone (Figure 2D). Taken together, the above findings demonstrate that the CD64 component of the recombinant receptor engages 


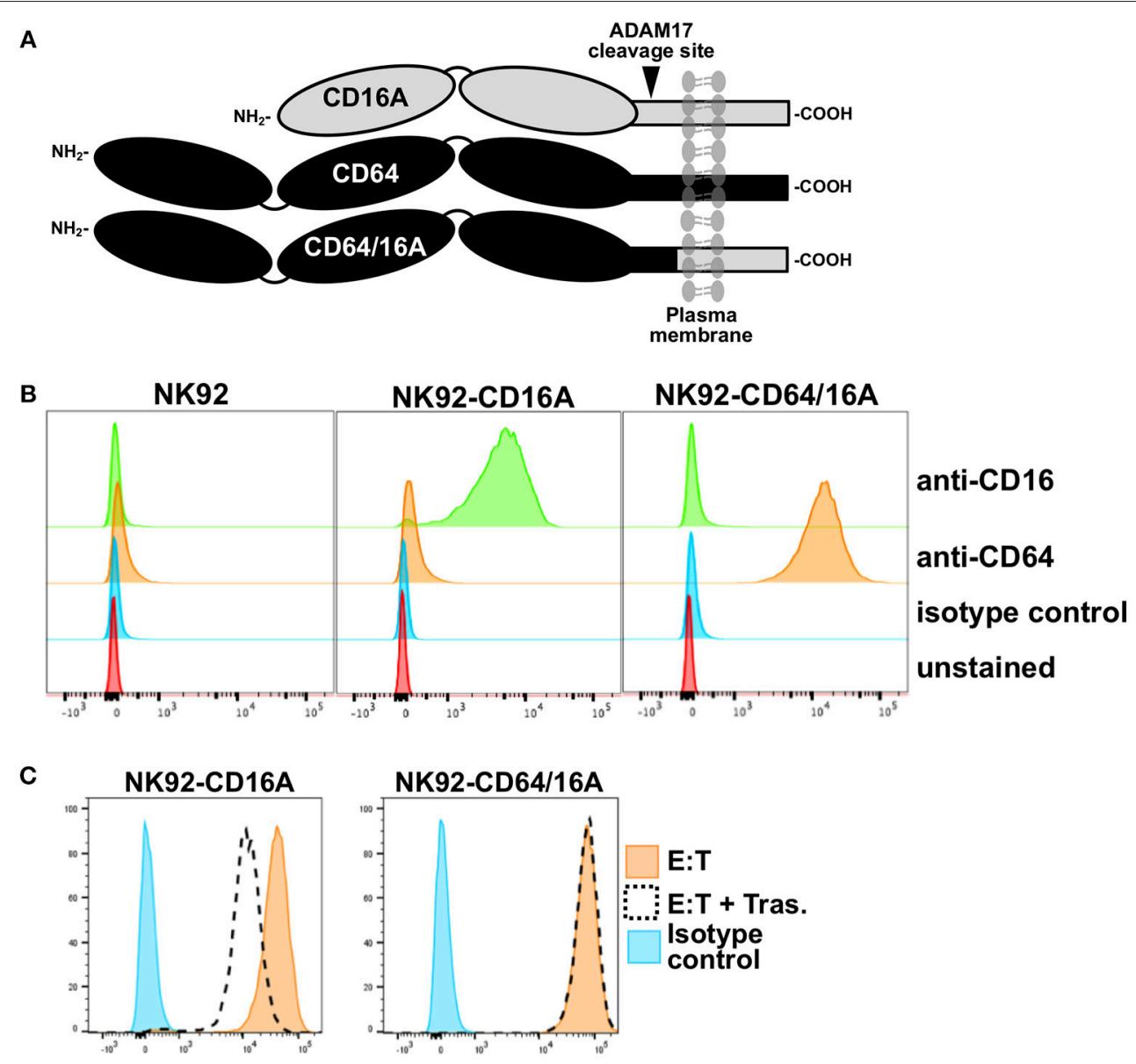

FIGURE 1 | Expression of CD64/16A by NK92 cells. (A) Schematic representation of the cell membrane forms of CD16A, CD64, and CD64/16A. CD16A undergoes ectodomain shedding by ADAM17 at a membrane proximal location, as indicated, which is not present in CD64 and CD64/16A. (B) NK92 parental cells, NK92-CD16A cells, and NK92-CD64/16A cells were stained with an anti-CD16, anti-CD64, or an isotype-matched negative control mAb and examined by flow cytometry. (C) NK92-CD16A and NK92-CD64/16A cells were incubated with SKOV-3 cells with or without trastuzumab $(5 \mu \mathrm{g} / \mathrm{ml})$ at $37^{\circ} \mathrm{C}\left(\mathrm{E}: \mathrm{T}=1: 1 ; 5 \times 10^{5} \mathrm{cells}\right.$ to $5 \times 10^{5}$ cells) for $2 \mathrm{~h}$. The NK92-CD16A and NK92-CD64/16A cells were then stained with an anti-CD16 mAb or an anti-CD64 mAb, respectively, and examined by flow cytometry. Non-specific antibody labeling was determined using the appropriate isotype-negative control mAb. (B,C) Data is representative of at least three independent experiments.

tumor-bound antibody, and that the CD16A component promotes intracellular signaling leading to degranulation and cytokine production.

\section{CD64/16A as a Docking Platform For Antibodies}

CD64 is distinguished from the other Fc $\gamma \mathrm{R}$ members by its unique third extracellular domain, which contributes to its high affinity and stable binding to soluble monomeric IgG (26). We compared the ability of NK92 cells expressing CD64/16A or the high affinity variant of CD16A (CD16A-176V) to capture soluble therapeutic mAbs. NK92 cell transductants expressing similar levels of CD64/16A and CD16A (Figure 3A) were incubated with trastuzumab for $2 \mathrm{~h}$. After which, excess antibody was washed away and the cells were stained with a fluorophoreconjugated anti-human IgG antibody and then evaluated by flow cytometry. As shown in Figure 3B, NK92-CD64/16A cells captured considerably higher levels of trastuzumab than did the NK92-CD16A cells (8.1-fold increase \pm 1.3 , mean \pm $S D$ of 3 independent experiments). In addition, the NK92CD64/16A cells efficiently captured the tumor-targeting mAbs Erbitux/cetuximab and Rituxan/rituximab, as well as the fusion protein L-selectin/Fc (Figure 3C). We then tested whether NK92-CD64/16A cells with a captured tumor-targeting mAb mediated ADCC. For this assay, we compared equal numbers of NK92-CD64/16A and NK92-CD16A cells that were incubated with the same concentration of soluble trastuzumab, washed, and exposed to SKOV-3 cells. We observed that target cell killing by NK92-CD64/16A cells with captured trastuzumab was significantly higher than by these same cells in the absence trastuzumab and was far superior to NK92-CD16A cells at all E: $\mathrm{T}$ ratios examined (Figure 3D). In contrast, SKOV-3 cytotoxicity by NK92-CD16A and NK92-CD64/16A cells was not significantly different if trastuzumab was present 
A

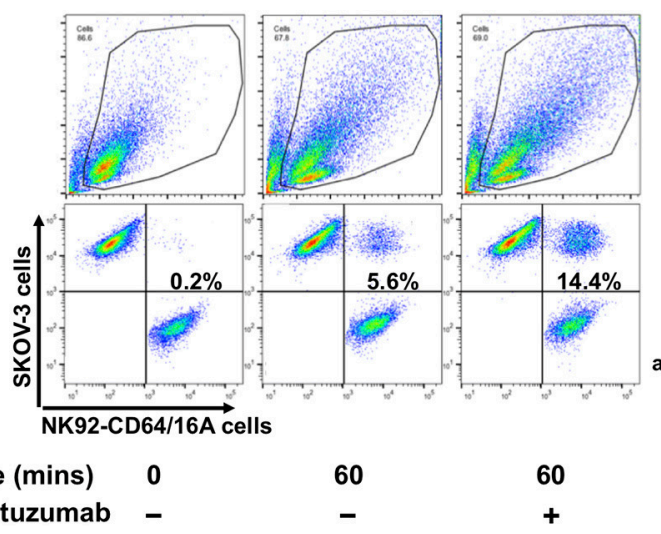

B

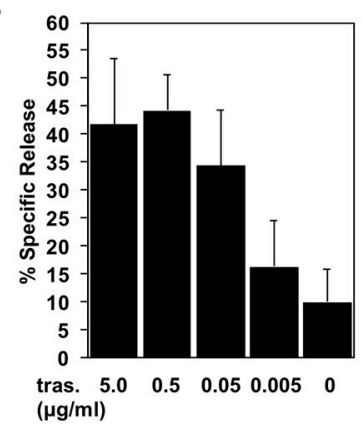

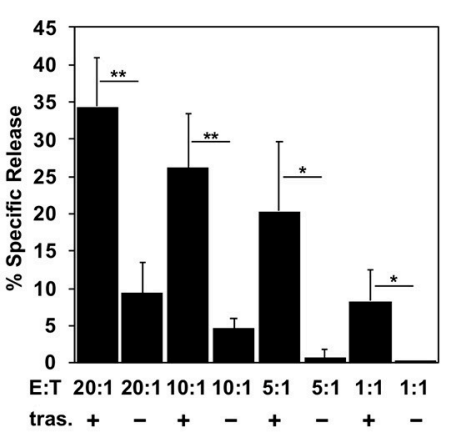

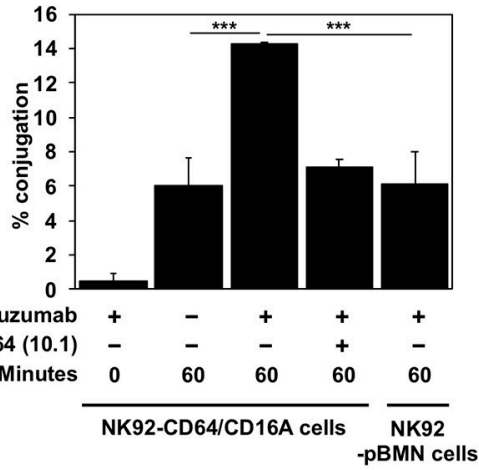

C

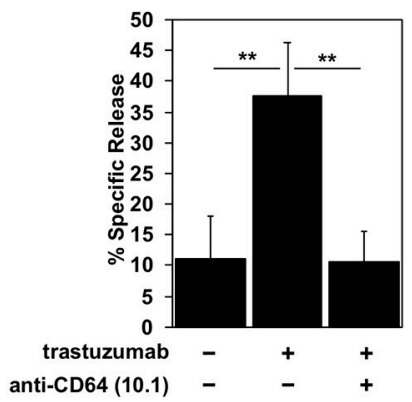

D

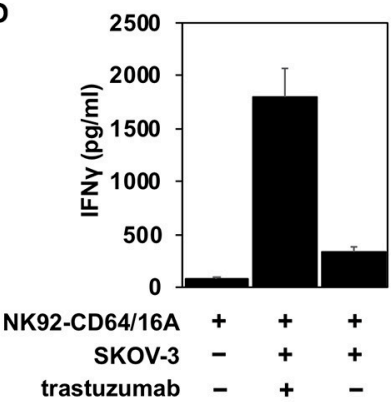

FIGURE 2 | CD64/16A promotes target cell conjugation, ADCC, and IFN $\gamma$ production. (A) NK92 control cells or NK92-CD64/16A cells, both expressing GFP, and SKOV-3 cells, labeled CellTrace Violet, were mixed at an E:T ratio of $1: 2\left(1 \times 10^{5}\right.$ cells to $2 \times 10^{5}$ cells $)$ in the presence or absence of trastuzumab $(5 \mu \mathrm{g} / \mathrm{ml})$ and the anti-CD64 mAb $10.1(10 \mu \mathrm{g} / \mathrm{ml})$, incubated at $37^{\circ} \mathrm{C}$ up to $60 \mathrm{~min}$, fixed, and then analyzed by flow cytometry, as described in the Materials and Methods. For the flow cytometric data, representative data are shown. For the bar graphs, mean $\pm S D$ of three independent experiments is shown. Statistical significance is indicated as ${ }^{* * *} p<0.001$. (B) NK92-CD64/16A cells were incubated with SKOV-3 cells (E:T $=20: 1 ; 1.6 \times 10^{5}$ cells to $8 \times 10^{3}$ cells) and trastuzumab (tras.) at the indicated concentrations (left panel), or with SKOV-3 cells at the indicated E:T ratios in the presence or absence of trastuzumab $(5 \mu \mathrm{g} / \mathrm{ml})\left(\right.$ (right panel) for $2 \mathrm{~h}$ at $37^{\circ} \mathrm{C}$. Data are represented as \% specific release and the mean \pm SD of 3 independent experiments is shown. Statistical significance is indicated as ${ }^{*} p<0.05,{ }^{* *} p<0.01$. (C) NK92-CD64/16A cells were incubated with SKOV-3 cells $\left(E: T=20: 1 ; 1.6 \times 10^{5}\right.$ cells to $8 \times 10^{3}$ cells) in the presence or absence of trastuzumab $(5 \mu \mathrm{g} / \mathrm{ml})$ and the anti-CD64 mAb $10.1(10 \mu \mathrm{g} / \mathrm{ml})$, as indicated, for $2 \mathrm{~h}$ at $37^{\circ} \mathrm{C}$. Data are represented as \% specific release and the mean $\pm S D$ of 3 independent experiments is shown. Statistical significance is indicated as ${ }^{* \star} p<0.01$. (D) NK92-CD64/16A cells were incubated with SKOV-3 cells (E:T $=1: 1 ; 1 \times 10^{5}$ cells to $1 \times 10^{5}$ cells) with or without trastuzumab $(5 \mu \mathrm{g} / \mathrm{ml})$ for $2 \mathrm{~h}$ at $37^{\circ} \mathrm{C}$. Secreted IFN $\gamma$ levels were quantified by ELISA. Data is shown as mean of 2 independent experiments.

during the assay and not initially docked to the transductants (Figure 3E). This demonstrates that the different transductants had an equivalent cytolytic capacity. Taken together, these findings show that NK92 cells expressing CD64/16A can stably bind soluble anti-tumor mAbs and IgG fusion proteins, and that these can serve as targeting elements to kill cancer cells.

\section{Expression and Function of CD64/16A in iPSC-Derived NK Cells}

We also examined the function of CD64/16A in engineered primary NK cells. Genetically modifying peripheral blood NK cells by retroviral or lentiviral transduction at this point has been challenging (35). Embryonic stem cells and iPSCs can be differentiated into cytolytic NK cells in vitro $(28-31,36)$, 
A

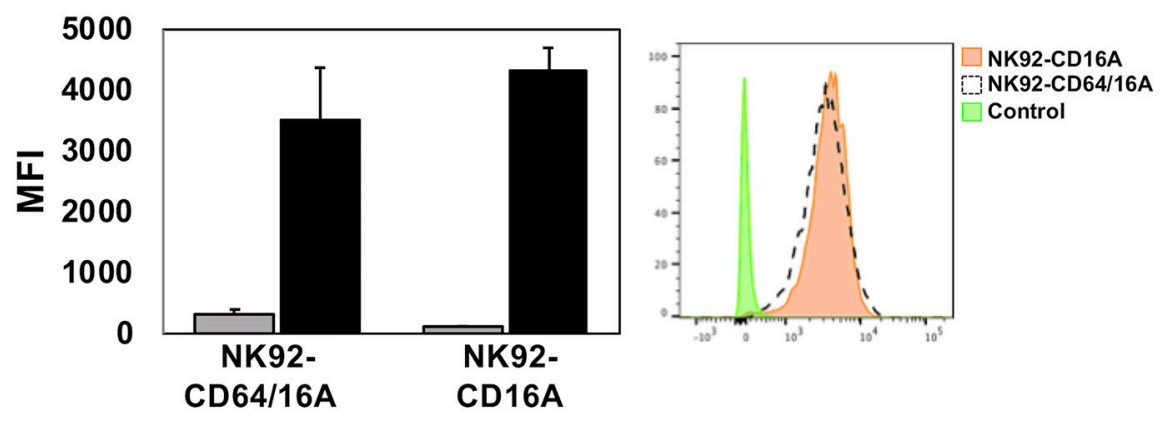

B

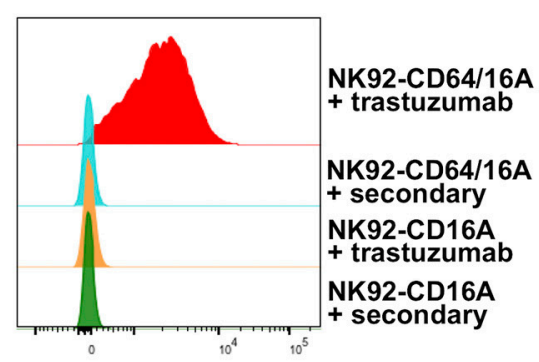

C

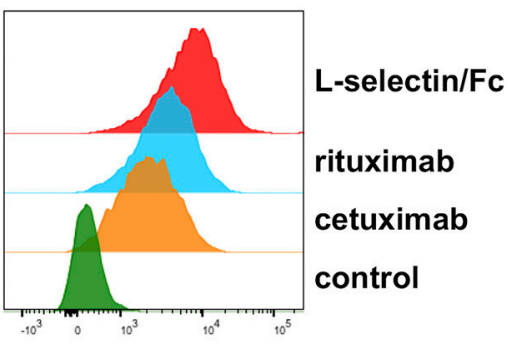

D

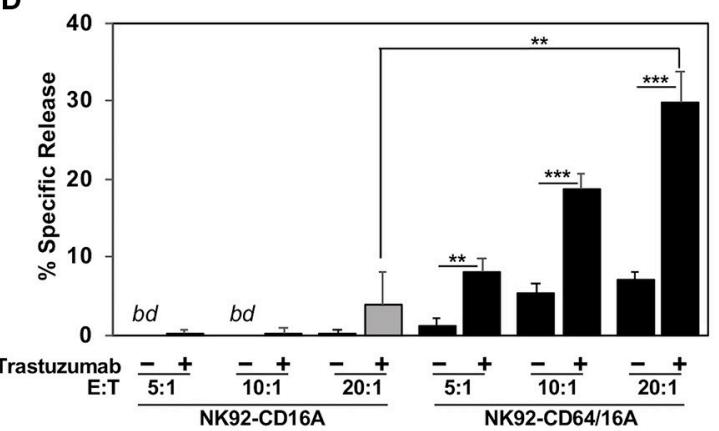

E

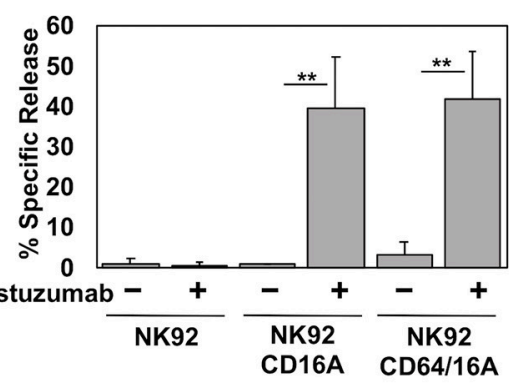

FIGURE 3 | CD64/16A attaches to soluble tumor-targeting mAbs and lgG fusion proteins. (A) Relative expression levels of CD16A and CD64/16A on NK92 cells were determined by cell staining with anti-CD16 and anti-CD64 mAbs (black bars), respectively, or an isotype-matched negative control antibody (gray bars). The bar graph shows mean fluorescence intensity (MFI) $\pm S D$ of three independent experiments. Representative flow cytometric data are shown in the histogram overlay. The dashed line histogram shows CD64 staining of NK92-CD64/16A cells, the orange-filled histogram shows CD16A staining of NK92-CD16A cells, and the green-filled histogram shows isotype control antibody staining of the NK92-CD16A cells. (B) NK92-CD16A and NK92-CD64/16A cells were incubated with or without trastuzumab $(5 \mu \mathrm{g} / \mathrm{ml})$ for $2 \mathrm{~h}$ at $37^{\circ} \mathrm{C}$, washed, stained with a fluorophore-conjugated anti-human secondary antibody, and analyzed by flow cytometry. Data is representative of at least 3 independent experiments. (C) NK92-CD64/16A cells were incubated with cetuximab or rituximab $(5 \mu \mathrm{g} / \mathrm{ml}$ for each), washed, and then stained with a fluorophore-conjugated anti-human secondary antibody. Control represents cells stained with the anti-human secondary antibody only. NK92-CD64/16A cells were also incubated with L-selectin/Fc $(5 \mu \mathrm{g} / \mathrm{ml})$, washed, and then stained with a fluorophore-conjugated anti-L-selectin mAb. NK92 cells lack expression of endogenous L-selectin (data not shown). All staining was analyzed by flow cytometry. Data shown are representative of 3 independent experiments. (D) NK92-CD16A and NK92-CD64/16A cells were incubated in the presence or absence of trastuzumab $(5 \mu \mathrm{g} / \mathrm{ml})$, washed, and exposed to SKOV-3 cells $\left(8 \times 10^{3}\right)$ at the indicated E:T cell ratios for $2 \mathrm{~h}$ at $37^{\circ} \mathrm{C}$. Data is shown as mean $\pm \mathrm{SD}$ of 3 independent experiments. Statistical significance is indicated as ${ }^{\star \star} p<0.01,{ }^{* \star *} p<$ 0.001. bd = below detection, (i.e., < spontaneous release by negative control cells). (E) NK92-CD16A and NK92-CD64/16A cells were incubated with SKOV-3 cells $\left(E: T=10: 1 ; 8 \times 10^{4}\right.$ cells to $8 \times 10^{3}$ cells $)$ in the presence or absence of trastuzumab $(5 \mu \mathrm{g} / \mathrm{ml})$, as indicated, for $2 \mathrm{~h}$ at $37^{\circ} \mathrm{C}$. Data is shown as mean $\pm \mathrm{SD}$ of 3 independent experiments. Statistical significance is indicated as ${ }^{\star *} p<0.01$.

and these cells are highly amendable to genetic engineering (14, 30, 37, 38). Undifferentiated iPSCs were transduced to express CD64/16A using a sleeping beauty transposon plasmid for non-random gene insertion and stable expression. iPSCs were differentiated into hematopoietic cells and then iNK cells by a two-step process that we have previously described $(14,28,29)$. For this study, we modified the hematopoietic differentiation method to streamline the procedure by using a commercially available media and hematopoietic differentiation kit, as described in the Materials and Methods. CD $34{ }^{+} \mathrm{CD} 43^{+} \mathrm{CD} 45^{+}$ cells were generated, further differentiated into iNK cells, and these cells were expanded for analysis using recombinant IL-2 and K562-mbIL21-41BBL feeder cells. CD56 ${ }^{+} \mathrm{CD} 3^{-}$is a hallmark phenotype of human NK cells, and these cells 

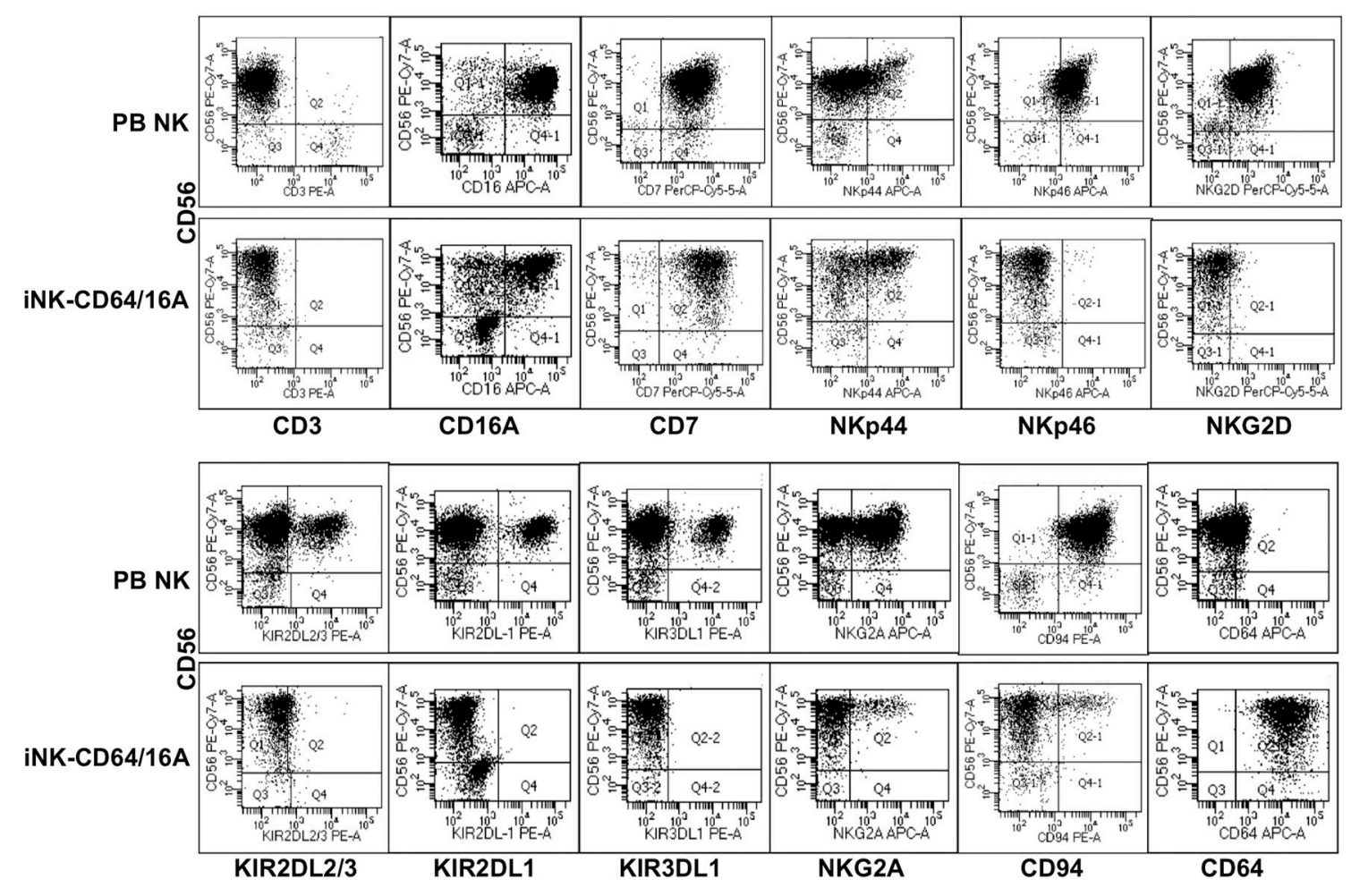

FIGURE 4 | Generation of iNK cells expressing CD64/CD16A. iPSCs were transduced to stably express CD64/16A, differentiated into NK cells, and then expanded using K562-mblL21-41BBL feeder cells, as described in the Materials and Methods. iNK-CD64/16A cells and freshly isolated peripheral blood (PB) NK cells were stained for CD56, CD3 and various inhibitory and activating receptors, as indicated. CD64/16A expression was determined by staining the cells with an anti-CD64 mAb. For the iNK-CD64/16A cells, representative data from at least three independent experiments are shown. For the PB NK cells, three separate blood donors were examined and data from one donor is shown.

composed the majority of our differentiated cell population (Figure 4). We also assessed the expression of a number of activating and inhibitory receptors on the iNK cells and compared this to freshly enriched, peripheral blood NK cells. The latter cells have heterogenous phenotypes among individuals and in particular for their inhibitory receptors (39-41). In contrast to the subsets of peripheral blood NK cells expressing the inhibitory KIR receptors KIR2DL2/3, KIR2DL1, and KIR3DL1, the expanded iNK cells lacked expression of these receptors and the activating receptors NKp46 and NKG2D (Figure 4). Of importance is that unlike peripheral blood NK cells, essentially all of the iNK cells were stained with an anti-CD64 mAb (Figure 4), demonstrating the expression of CD64/16A.

To assess the function of CD64/16A, we compared iNK cells derived from iPSCs transduced with either a pKT2 empty vector or pKT2-CD64/16A. The NK cell markers mentioned above were expressed at similar levels and proportions by the two iNK cell populations (data not shown), including CD16A (Figure 5A), but only the iNK-CD64/16A cells were stained by an anti-CD64 $\mathrm{mAb}$ (Figure 5A). Both iNK transductants demonstrated increased SKOV-3 cell killing when in the presence of trastuzumab, yet iNK-CD64/16A cells mediated significantly higher levels of ADCC than did the iNK-pKT2 control cells (Figure 5B). The anti-CD16 function blocking mAb 3G8, but not the anti-CD64 mAb 10.1, effectively inhibited ADCC by the iNK-pKT2 cells (Figure 5B). Conversely, 10.1, but not 3G8, blocked ADCC by the iNK-CD64/16A cells (Figure 5B). These findings show that the generated iNK cells were cytolytic effectors responsive to CD16A and CD64/16A engagement of antibody-bound tumor cells. We also treated iNK-CD64/16A and iNK-pKT2 cells with soluble trastuzumab, washed away excess antibody, and exposed them to SKOV-3 cells. Under these conditions, ADCC by the iNK-CD64/16A cells was markedly higher than the iNK-pKT2 cells (Figure 5C), further establishing that CD64/16A can capture soluble antitumor mAbs that serve as a targeting element for tumor cell killing.

\section{DISCUSSION}

CD16A has an exclusive role in inducing ADCC by human NK cells (2-4). The affinity of antibody binding and the expression levels of this IgG Fc receptor modulate NK cell effector functions and affect the efficacy of tumor-targeting therapeutic mAbs $(4,11,19,20)$. To enhance anti-tumor antibody binding by NK cells, we expressed a novel recombinant $\mathrm{F} C \gamma \mathrm{R}$ consisting of the extracellular region of the high affinity 


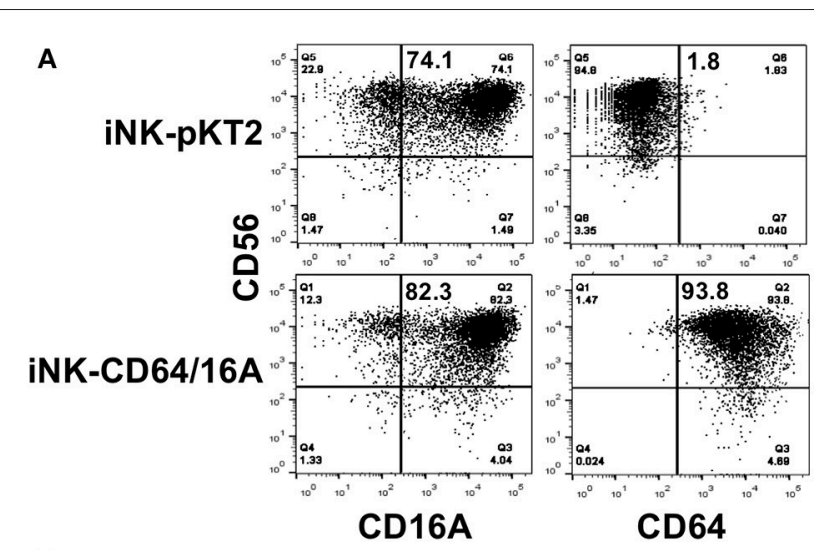

B
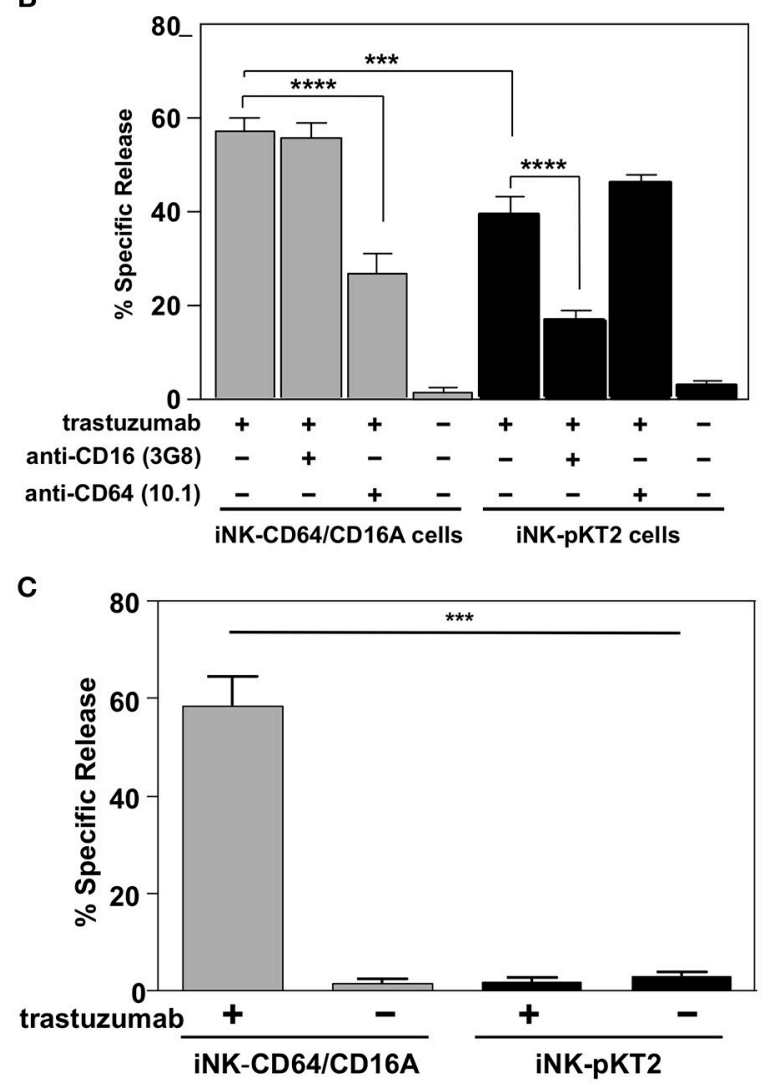

FIGURE 5 | iNK-CD64/16A cells show enhanced ADCC compared to iNK-pKT2 control cells. (A) iNK cells derived from empty vector (iNK-pKT2) or CD64/16A (iNK-CD64/16A) transduced iPSCs were stained for CD56, CD64, and CD16A, as indicated. The percentage of $\mathrm{CD}^{+} 6^{+}$cells positively staining for CD16A or CD64 are indicated in the top right quadrant. (B) iNK-pKT2 or iNK-CD64/16A cells were incubated with SKOV-3 cells (E:T $=10: 1 ; 8 \times 10^{4}$ cells to $8 \times 10^{3}$ cells) in the presence or absence of trastuzumab $(5 \mu \mathrm{g} / \mathrm{ml})$, the function blocking anti-CD16 mAb $3 G 8(5 \mu \mathrm{g} / \mathrm{ml})$, and the function blocking anti-CD64 mAb $10.1(5 \mu \mathrm{g} / \mathrm{ml})$, as indicated, for $2 \mathrm{~h}$ at $37^{\circ} \mathrm{C}$. Data is shown as mean $\pm \mathrm{SD}$ of three independent experiments. Statistical significance is indicated as ${ }^{* \star *} p<0.001 ;{ }^{* \star * \star} p<0.0001$. (C) iNK-pKT2 and iNK-CD64/16A cells were incubated in the presence or absence of trastuzumab $(5 \mu \mathrm{g} / \mathrm{ml})$, washed, and exposed to SKOV-3 cells $\left(E: T=10: 1 ; 8 \times 10^{4}\right.$ cells to $8 \times 10^{3}$ cells) for $2 \mathrm{~h}$ at $37^{\circ} \mathrm{C}$. Data is shown as mean $\pm S D$ of three independent experiments. Statistical significance is indicated as ${ }^{* \star} p<0.001$.
$\mathrm{F} c \gamma \mathrm{R}$ CD64 and the transmembrane and intracellular regions of CD16A. NK cells expressing CD64/16A facilitated cell conjugation with antibody-bound tumor cells, cytotoxicity, and IFN $\gamma$ production, demonstrating function by both components of the recombinant Fc $\gamma \mathrm{R}$. CD64/16A lacks the ADAM17 cleavage region found in $\mathrm{CD} 16 \mathrm{~A}$ and it did not undergo the same level of downregulation in expression during ADCC. Moreover, consistent with the ability of CD64 to stably bind soluble monomeric IgG, NK cells expressing CD64/16A could capture soluble anti-tumor therapeutic mAbs and kill target cells.

We demonstrate that CD64/16A was functional in two human NK cell platforms, the NK92 cell line and primary NK cells derived from iPSCs. NK92 cells lack inhibitory KIR receptors and show high levels of natural cytotoxicity compared to other NK cell lines derived from patients (42). NK92 cells have been widely used to express modified genes to direct their cytolytic effector function, have been evaluated in preclinical studies, and are undergoing clinical testing in cancer patients $(42,43)$. iPSCs are also very amendable to genetic engineering and can be differentiated into NK cells expressing various receptors to direct their effector functions $(14,30,37,38)$. For this study, we streamlined and standardized the hematopoietic differentiation step using a commercial kit. Though the generated iNK cells lacked several inhibitory and activating receptors compared to peripheral blood NK cells and iNK cells in previous studies (2931 ), the majority of the cells were $\mathrm{CD} 16 \mathrm{~A}^{+}$, which is expressed by mature NK cells (44), and mediated ADCC, demonstrating they were cytotoxic effector cells. The particular phenotype of the iNK cells will be important for the desired effector functions. However, to better direct and enhance their antitumor activity through the expression of engineered receptors and reduce their off-target effects, it may be advantageous for the iNK cells not to express endogenous inhibitory and activating receptors. Tumor cell ADCC by iNK cells expressing CD64/16A cells was significantly blocked by an anti-CD64 mAb. Interestingly, in contrast to pKT2 vector control iNK cells, ADCC by the iNK-CD64/16A cells was not blocked by an antiCD16 mAb. Why endogenous CD16A in the iNK-CD64/16A cells did not have a role in the in vitro ADCC assay is unclear at this time. This may be due to a competitive advantage by CD64/16A over endogenous CD16A in binding antibody and/or in utilizing the same pool of downstream signaling factors.

An individual NK cell can kill multiple tumor cells in different manners. This includes by a process of sequential contacts and degranulations, referred to as serial killing (45, 46 ), and by the localized dispersion of its granule contents that kills surrounding tumor cells, referred to as bystander killing (47). Further studies are required to determine the effects of CD64/16A expression on these killing processes during ADCC. Inhibiting CD16A shedding has been reported to slow NK cell detachment from target cells and reduce serial killing by NK cells in vitro (48). Due to the CD64 component and its lack of ectodomain shedding, NK cells expressing CD64/16A could be less efficient at serial killing 
and more efficient at bystander killing. An important next step will be to assess the anti-tumor activity of NK cells expressing CD64/16A in vivo, which will include the use of NK92CD64/16A cells and iNK-CD64/16A cells in tumor xenograft models.

Therapeutic mAbs have become one of the fastest growing classes of drugs, and tumor-targeting mAbs are the most widely used and characterized immunotherapy for hematologic and solid tumors (49). NK cells expressing CD64/16A have several potential advantages as a combination therapy, as their capture of anti-tumor mAbs, either individually or when mixed, prior to adoptive transfer provides diverse options for switchable targeting elements. Modifying NK cells expressing CD64/16A with an antibody would also reduce the dosage of therapeutic antibodies administered to patients. We showed that fusion proteins containing a human IgG Fc region, such as L-selectin/Fc, can also be captured by CD64/16A, which may provide further options for directing the tissue and tumor antigen targeting of engineered NK cells. Advantages of the NK92 and iNK cell platforms for adoptive cell therapies is that they can be readily gene modified on a clonal level and expanded into clinicalscalable cell numbers to produce engineered NK cells with

\section{REFERENCES}

1. Carotta S. Targeting NK cells for anticancer immunotherapy: clinical and preclinical approaches. Front Immunol. (2016) 7:152. doi: 10.3389/fimmu.2016.00152

2. Alderson KL, Sondel PM. Clinical cancer therapy by NK cells via antibody-dependent cell-mediated cytotoxicity. J Biomed Biotechnol. (2011) 2011:379123. doi: 10.1155/2011/379123

3. Long EO, Kim HS, Liu D, Peterson ME, Rajagopalan S. Controlling natural killer cell responses: integration of signals for activation and inhibition. Annu Rev Immunol. (2013) 31:227-58. doi: 10.1146/annurev-immunol-020711-075005

4. Wang W, Erbe AK, Hank JA, Morris ZS, Sondel PM. NK Cellmediated antibody-dependent cellular cytotoxicity in cancer immunotherapy. Front Immunol. (2015) 6:368. doi: 10.3389/fimmu.2015. 00368

5. Lanier LL, Yu G, Phillips JH. Co-association of CD3 zeta with a receptor (CD16) for IgG Fc on human natural killer cells. Nature (1989) 342:803-5. doi: 10.1038/342803a0

6. Anderson P, Caligiuri M, O’Brien C, Manley T, Ritz J, Schlossman SF. Fc gamma receptor type III (CD16) is included in the zeta NK receptor complex expressed by human natural killer cells. Proc Natl Acad Sci USA. (1990) 87:2274-8.

7. Letourneur O, Kennedy IC, Brini AT, Ortaldo JR, O'Shea JJ, Kinet JP. Characterization of the family of dimers associated with $\mathrm{FC}_{\mathrm{C}}$ receptors (FC epsilon RI and Fc gamma RIII). J Immunol. (1991) 147:2652-6.

8. Hou X, Dietrich J, Geisler NO. The cytoplasmic tail of FcgammaRIIIAalpha is involved in signaling by the low affinity receptor for immunoglobulin G. J Biol Chem. (1996) 271:22815-22.

9. Li X, Baskin JG, Mangan EK, Su K, Gibson AW, Ji C, et al. The unique cytoplasmic domain of human FcgammaRIIIA regulates receptormediated function. J Immunol. (2012) 189:4284-94. doi: 10.4049/jimmunol.12 00704

10. Wang Y, Wu J, Newton R, Bahaie NS, Long C, Walcheck B. ADAM17 cleaves CD16b (FcgammaRIIIb) in human neutrophils. Biochim Biophys Acta (2013) 1833:680-5. doi: 10.1016/j.bbamcr.2012.11.027

11. Romee R, Foley B, Lenvik T, Wang Y, Zhang B, Ankarlo D, et al. NK cell CD16 surface expression and function is regulated by a improved effector activities as an off-the-shelf therapeutic for cancer immunotherapy $(36,37,42,43,50)$.

\section{AUTHOR CONTRIBUTIONS}

BW and JW collected, assembled, analyzed, and interpreted the data, and wrote the manuscript. KS collected, analyzed, and interpreted the data, and revised the manuscript. RH, HM, $\mathrm{DM}$, YL, and AR collected, analyzed, and interpreted the data. DK analyzed the data and revised the manuscript. All authors contributed to manuscript preparation, read, and approved the submitted version.

\section{FUNDING}

This work was supported by grants from the NIH, award numbers R01CA203348 and R21AI125729, and the Minnesota Ovarian Cancer Alliance. KS was supported by a Howard Hughes Medical Institute and Burroughs Wellcome Fund Medical Research Fellowship. AR was supported by the Office of the Director of the NIH, award number T35OD0 11118.

disintegrin and metalloprotease-17 (ADAM17). Blood (2013) 121:3599-608. doi: 10.1182/blood-2012-04-425397

12. Peruzzi G, Femnou L, Gil-Krzewska A, Borrego F, Weck J, Krzewski K, et al. Membrane-type 6 matrix metalloproteinase regulates the activation-induced downmodulation of CD16 in human primary NK cells. J Immunol. (2013) 191:1883-94. doi: 10.4049/jimmunol.1300313

13. Lajoie L, Congy-Jolivet N, Bolzec A, Gouilleux-Gruart V, Sicard E, Sung HC, et al. ADAM17-mediated shedding of FcgammaRIIIA on human NK cells: identification of the cleavage site and relationship with activation. J Immunol. (2014) 192:741-51. doi: 10.4049/jimmunol.1301024

14. Jing $\mathrm{Y}, \mathrm{Ni} \mathrm{Z}, \mathrm{Wu}$ J, Higgins L, Markowski TW, Kaufman DS, et al. Identification of an ADAM17 cleavage region in human CD16 (FcgammaRIII) and the engineering of a non-cleavable version of the receptor in NK cells. PLoS ONE (2015) 10:e0121788. doi: 10.1371/journal.pone.01 21788

15. Lai P, Rabinowich H, Crowley-Nowick PA, Bell MC, Mantovani G, Whiteside TL. Alterations in expression and function of signal-transducing proteins in tumor-associated $\mathrm{T}$ and natural killer cells in patients with ovarian carcinoma. Clin Cancer Res. (1996) 2:161-73.

16. Veeramani S, Wang SY, Dahle C, Blackwell S, Jacobus L, Knutson T, et al. Rituximab infusion induces NK activation in lymphoma patients with the high-affinity CD16 polymorphism. Blood (2011) 118:3347-9. doi: 10.1182/blood-2011-05-351411

17. Cox MC, Battella S, La Scaleia R, Pelliccia S, Di Napoli A, Porzia A, et al. Tumor-associated and immunochemotherapy-dependent long-term alterations of the peripheral blood NK cell compartment in DLBCL patients. Oncoimmunology (2015) 4:e990773. doi: 10.4161/2162402X.2014.990773

18. Granzin M, Soltenborn S, Muller S, Kollet J, Berg M, Cerwenka A, et al. Fully automated expansion and activation of clinical-grade natural killer cells for adoptive immunotherapy. Cytotherapy (2015) 17:621-32. doi: 10.1016/j.jcyt.2015.03.611

19. Felices M, Chu S, Kodal B, Bendzick L, Ryan C, Lenvik AJ, et al. IL-15 superagonist (ALT-803) enhances natural killer (NK) cell function against ovarian cancer. Gynecol Oncol. (2017) 145:453-61. doi: 10.1016/j.ygyno.2017.02.028

20. Mishra HK, Pore N, Michelotti EF, Walcheck B. Anti-ADAM17 monoclonal antibody MEDI3622 increases IFNgamma production by human NK cells in the presence of antibody-bound tumor cells. Cancer Immunol Immunother. (2018) 67:1407-16. doi: 10.1007/s00262-018-2193-1 
21. Wu J, Edberg JC, Redecha PB, Bansal V, Guyre PM, Coleman K, et al. A novel polymorphism of FcgammaRIIIa (CD16) alters receptor function and predisposes to autoimmune disease. J Clin Invest. (1997) 100:1059-70. doi: 10.1172/JCI119616

22. Koene HR, Kleijer M, Algra J, Roos D, von dem Borne AE, de Haas M. Fc gammaRIIIa-158V/F polymorphism influences the binding of IgG by natural killer cell Fc gammaRIIIa, independently of the Fc gammaRIIIa-48L/R/H phenotype. Blood (1997) 90:1109-14.

23. Dong C, Ptacek TS, Redden DT, Zhang K, Brown EE, Edberg JC, et al. Fcgamma receptor IIIa single-nucleotide polymorphisms and haplotypes affect human IgG binding and are associated with lupus nephritis in African Americans. Arthr Rheumatol. (2014) 66:1291-9. doi: 10.1002/art.38337

24. Nimmerjahn F, Ravetch JV. Fcgamma receptors as regulators of immune responses. Nat Rev Immunol. (2008) 8:34-47. doi: 10.1038/nri2206

25. Bruhns P, Iannascoli B, England P, Mancardi DA, Fernandez N, Jorieux $S$, et al. Specificity and affinity of human Fcgamma receptors and their polymorphic variants for human IgG subclasses. Blood (2009) 113:3716-25. doi: 10.1182/blood-2008-09-179754

26. Kiyoshi M, Caaveiro JM, Kawai T, Tashiro S, Ide T, Asaoka Y, et al. Structural basis for binding of human IgG1 to its high-affinity human receptor FcgammaRI. Nat Commun. (2015) 6:6866. doi: 10.1038/ncomms7866

27. Binyamin L, Alpaugh RK, Hughes TL, Lutz CT, Campbell KS, Weiner LM. Blocking NK cell inhibitory self-recognition promotes antibody-dependent cellular cytotoxicity in a model of anti-lymphoma therapy. J Immunol. (2008) 180:6392-401. doi: 10.4049/jimmunol.180.9.6392

28. Ni Z, Knorr DA, Kaufman DS. Hematopoietic and nature killer cell development from human pluripotent stem cells. Methods Mol Biol. (2013) 1029:33-41. doi: 10.1007/978-1-62703-478-4_3

29. Knorr DA, Ni Z, Hermanson D, Hexum MK, Bendzick L, Cooper LJ, et al. Clinical-scale derivation of natural killer cells from human pluripotent stem cells for cancer therapy. Stem Cells Transl Med. (2013) 2:274-83. doi: 10.5966/sctm.2012-0084

30. Ni Z, Knorr DA, Bendzick L, Allred J, Kaufman DS. Expression of chimeric receptor CD4zeta by natural killer cells derived from human pluripotent stem cells improves in vitro activity but does not enhance suppression of HIV infection in vivo. Stem cells (2014) 32:1021-31. doi: 10.1002/stem.1611

31. Hermanson DL, Bendzick L, Pribyl L, McCullar V, Vogel RI, Miller JS, et al. Induced pluripotent stem cell-derived natural killer cells for treatment of ovarian cancer. Stem Cells (2016) 34:93-101. doi: 10.1002/ stem. 2230

32. Woll PS, Grzywacz B, Tian X, Marcus RK, Knorr DA, Verneris MR, et al. Human embryonic stem cells differentiate into a homogeneous population of natural killer cells with potent in vivo antitumor activity. Blood (2009) 113:6094-101. doi: 10.1182/blood-2008-06-165225

33. Harrison PT, Allen JM. High affinity IgG binding by FcgammaRI (CD64) is modulated by two distinct IgSF domains and the transmembrane domain of the receptor. Protein Eng. (1998) 11:225-32.

34. Wang R, Jaw JJ, Stutzman NC, Zou Z, Sun PD. Natural killer cell-produced IFN-gamma and TNF-alpha induce target cell cytolysis through up-regulation of ICAM-1. J Leukoc Biol. (2012) 91:299-309. doi: 10.1189/jlb.0611308

35. Carlsten M, Childs RW. Genetic manipulation of NK cells for cancer immunotherapy: techniques and clinical implications. Front Immunol. (2015) 6:266. doi: 10.3389/fimmu.2015.00266

36. Zeng J, Tang SY, Toh LL, Wang S. Generation of “Off-the-Shelf” natural killer cells from peripheral blood cell-derived induced pluripotent stem cells. Stem Cell Rep. (2017) 9:1796-812. doi: 10.1016/j.stemcr.2017.10.020

37. Hermanson DL, Kaufman DS. Utilizing chimeric antigen receptors to direct natural killer cell activity. Front Immunol. (2015) 6:195. doi: 10.3389/fimmu.2015.00195
38. Li Y, Hermanson DL, Moriarity BS, Kaufman DS. Human iPSCderived natural killer cells engineered with chimeric antigen receptors enhance anti-tumor activity. Cell Stem Cell (2018) 23:181-192.e5. doi: 10.1016/j.stem.2018.06.002

39. Strauss-Albee DM, Horowitz A, Parham P, Blish CA. Coordinated regulation of $\mathrm{NK}$ receptor expression in the maturing human immune system. J Immunol. (2014) 193:4871-9. doi: 10.4049/jimmunol.1401821

40. Horowitz A, Strauss-Albee DM, Leipold M, Kubo J, Nemat-Gorgani N, Dogan OC, et al. Genetic and environmental determinants of human NK cell diversity revealed by mass cytometry. Sci Transl Med. (2013) 5:208ra145. doi: $10.1126 /$ scitranslmed.3006702

41. Strauss-Albee DM, Fukuyama J, Liang EC, Yao Y, Jarrell JA, Drake AL, et al. Human NK cell repertoire diversity reflects immune experience and correlates with viral susceptibility. Sci Transl Med. (2015) 7:297ra115. doi: 10.1126/scitranslmed.aac5722

42. Klingemann H, Boissel L, Toneguzzo F. Natural killer cells for immunotherapy - advantages of the NK-92 cell line over blood NK Cells. Front Immunol. (2016) 7:91. doi: 10.3389/fimmu.2016.00091

43. Zhang C, Oberoi P, Oelsner S, Waldmann A, Lindner A, Tonn T, et al. Chimeric antigen receptor-engineered NK-92 Cells: an off-theshelf cellular therapeutic for targeted elimination of cancer cells and induction of protective antitumor immunity. Front Immunol. (2017) 8:533. doi: 10.3389/fimmu.2017.00533

44. Seidel UJ, Schlegel P, Lang P. Natural killer cell mediated antibody-dependent cellular cytotoxicity in tumor immunotherapy with therapeutic antibodies. Front Immunol. (2013) 4:76. doi: 10.3389/fimmu.2013.00076

45. Bhat R, Watzl C. Serial killing of tumor cells by human natural killer cells-enhancement by therapeutic antibodies. PLoS ONE (2007) 2:e326. doi: 10.1371/journal.pone.0000326

46. Vanherberghen B, Olofsson PE, Forslund E, Sternberg-Simon M, Khorshidi MA, Pacouret S, et al. Classification of human natural killer cells based on migration behavior and cytotoxic response. Blood (2013) 121:1326-34. doi: 10.1182/blood-2012-06-439851

47. Hsu HT, Mace EM, Carisey AF, Viswanath DI, Christakou AE, Wiklund $\mathrm{M}$, et al. NK cells converge lytic granules to promote cytotoxicity and prevent bystander killing. J Cell Biol. (2016) 215:875-89. doi: 10.1083/jcb.2016 04136

48. Srpan K, Ambrose A, Karampatzakis A, Saeed M, Cartwright ANR, Guldevall $\mathrm{K}$, et al. Shedding of CD16 disassembles the NK cell immune synapse and boosts serial engagement of target cells. J Cell Biol. (2018) 217:3267. doi: $10.1083 /$ jcb. 201712085

49. Battella S, Cox MC, Santoni A, Palmieri G. Natural killer (NK) cells and anti-tumor therapeutic mAb: unexplored interactions. J Leukoc Biol. (2016) 99:87-96. doi: 10.1189/jlb.5VMR0415-141R

50. Angelos MG, Kaufman DS. Pluripotent stem cell applications for regenerative medicine. Curr Opin Organ Transplant. (2015) 20:663-70. doi: 10.1097/MOT.0000000000000244

Conflict of Interest Statement: The authors declare that the research was conducted in the absence of any commercial or financial relationships that could be construed as a potential conflict of interest.

Copyright (C) 2018 Snyder, Hullsiek, Mishra, Mendez, Li, Rogich, Kaufman, Wu and Walcheck. This is an open-access article distributed under the terms of the Creative Commons Attribution License (CC BY). The use, distribution or reproduction in other forums is permitted, provided the original author(s) and the copyright owner(s) are credited and that the original publication in this journal is cited, in accordance with accepted academic practice. No use, distribution or reproduction is permitted which does not comply with these terms. 